\title{
Strategic Knowledge Management as Means of Ensuring the Competitiveness of Railway Transport Enterprises
}

\author{
Volodymyr Dykan ${ }^{1}$, Viktoria Ovchynnikova ${ }^{1 *}$, Valeria Dykan ${ }^{2}$, Natalia Kalicheva $^{1}$ and \\ Myroslava Korin ${ }^{1}$ \\ ${ }^{1}$ Ukrainian State University of Railway Transport, Economy and Management of Industrial and \\ Commerce Business Department, Feuerbach sq. 7, 61050 Kharkiv, Ukraine \\ ${ }^{2}$ Karazin business school, management and administration Department, Mironositska st., 1, 61001 \\ Kharkiv, Ukraine
}

\begin{abstract}
In article timeliness and expediency of application of strategic management of knowledge as effective means of ensuring competitiveness of the enterprises of railway transport is proved. Analysis of existing models of knowledge management has led to the conclusion that each of the existing models of knowledge management requires certain conditions regarding the possibility of its use. First of all, it is the presence of a stable organizational culture in the enterprise, a favorable moral climate, the initiative of employees, in fact, is a prerequisite for the creation of implicit knowledge, attention to the value of human and intellectual capital on the part of management, as well as the possibility of accumulating knowledge for their further analysis, use and improvement. This created the basis for improving the conceptual provisions of strategic knowledge management in railway transport, revealing management technologies in the following areas: the development of competencies of personnel focused on the implementation of strategic objectives; the creation of a comprehensive integrated information environment that improves the quality of business processes; the implementation of effective interaction of railway transport with stakeholders to improve its image; the formation of knowledge subsystem of economic security management.
\end{abstract}

\section{Problem statement and its connection with scientific or practical tasks}

The formation and development of market relations in our country is highly dependent on the conditions in which business entities are forced to conduct economic activity. The competition continues between enterprises, it is a feature inherent to competitive relations. In order to survive the competition and make a profit, railway transport enterprises must constantly ensure their competitiveness and maintain it at a sufficient level.

\footnotetext{
*Corresponding author: vikols75@ukr.net
} 
Strengthening of crisis phenomena and transformation processes occurring in the world and domestic economic and transport systems, determine the need for new approaches and directions to improve the efficiency of railway transport. In the context of fierce competition in the domestic and world markets of transport services, one of the most effective tools to improve the efficiency of rail transport is to change the organizational and economic approaches and means of ensuring their competitiveness, of particular importance among which is knowledge management.

\section{Analysis of recent research and publications}

The problems of ensuring the competitiveness of rail transport, in particular through knowledge management, deals with a significant number of scientists and practitioners, among which are the works by V. Dykan, I. Tokmakova, V. Ovchynnikova, M. Porter, V. Shynkarenko, A. Bondarenko, N. Kalycheva, E. Sych, et al. [1-8]. During the research conceptual framework on this topic found that you can singled out three areas of knowledge management and "European", considering the knowledge management from the perspective of measurement (Karl Sveiby), the "American" approach is the direct "knowledge management" (Karl Wiig) and focuses on the "creation of knowledge" (by Ikujiro Nonaka and Hirotaka Takeuchi). The Japanese approach characterizes the four-phase model of knowledge management SECI, or "spiral of knowledge", proposed by Japanese researchers I. Nonaka and H. Takeuchi [6], which is a system of knowledge transfer between the four phases and socialization, externalization, combination, internalization and through three levels of social aggregation, namely: individual, group, context.

The representatives of the European approach K. Sveiby, L. Edvinsson [7] model of knowledge management from the perspective of the intellectual capital of enterprises, which represents the interaction of four components: human capital, structural capital, business assets and intellectual property. Such models are purely theoretical in nature, and its practical use is complicated by the burden of managing individual business processes.

The American approach proposed by K. Wiing [8] reveals the model of knowledge management based on four main provisions: the creation and application of knowledge in production technologies and procedures, systematic knowledge research, knowledge assessment for each type of business and active knowledge management throughout the life cycle of goods and innovations. However, there are a number of limitations that do not allow effective use of this model in practice. In particular, it is the probability of problems in the process of assessing knowledge, methods and procedures of assessment, the controversy of their results on the basis of which, in fact, there is knowledge management.

Having analyzed the existing models of knowledge management, we state that each of the models of knowledge management requires certain conditions regarding the possibilities of its use. First of all, it is the presence of a stable organizational culture in the enterprise, a favorable moral climate, the initiative of employees, in fact, is a prerequisite for the creation of implicit knowledge, attention to the value of human and intellectual capital on the part of management, as well as the possibility of accumulating knowledge for their further analysis, use and improvement. This will create a basis for further improvement of the conceptual provisions of strategic knowledge management in railway transport, will contribute to the competitiveness of the industry.

\section{Conceptual provisions of knowledge management in railway transport}


The beginning of the new millennium is marked by the entry of human society into a phase of its development, when knowledge becomes the main source of competitive advantages of individuals and organizations. Information and knowledge produced on its basis allow responding quickly and adequately to changes in the external and internal environment of the organization. Awareness of knowledge as an economic resource, vital for the activities of companies, is a good reason for their inclusion in the sphere of management.

In the modern economy of knowledge is really becoming the main driving force of socio-economic development. The generation of new knowledge acquires the status of a priority strategic activity in the course of which a competitive product (work, services) is produced.

Knowledge management includes the following components [8, 9]: the stimulation of the growth of knowledge; selection and storage of meaningful information from external to the organization sources; the preservation, classification, transformation, ensuring the availability of knowledge; the dissemination and exchange of knowledge, including in the framework of the organization; knowledge in business processes, particularly in decisionmaking; the embodiment of knowledge in products, services, documents, databases, and software; evaluation, measurement, and use of intangible assets of the organization; protecting knowledge.

The basic principles of knowledge management include: the principle of science (involves the construction of a knowledge management system based on scientific recommendations, which requires the use of the full range of modern scientific achievements); the principle of consistency (involves taking into account the interaction and interdependence of all components of the knowledge management system in the enterprise); the principle of temporality (includes accounting for the value of the environment and feedback to the success of the enterprise, management decisions based on the study of the totality of situational factors); the principle of understanding and use of psychological factors (involves the creation of conditions for the most complete realization of the personal potential of each employee and the optimization of interpersonal relationships in the team); the principle of authority and responsibility (is that each employee must have sufficient authority to be responsible for the quality of the work); the principle of democratic centralism (provides for the granting of autonomy with the preservation of the leadership of the coordination functions); the principle of integration the effectiveness of knowledge management depends on the successful integration of skills, knowledge, experience, scientific potential, etc.; the principle of development of conditions and opportunities is that it is necessary to create such conditions under which participants of knowledge management possess all information, analyze and consider organizational culture, know all fundamental provisions; the principle of ensuring the novelty of knowledge - knowledge changes over time, become obsolete: knowledge has a natural life cycle, so some elements of knowledge must be constantly updated; the principle of remuneration for knowledge and the necessary monitoring and analysis of the results of the creation, application and development of knowledge; the principle of turning knowledge into action is to create new knowledge and use it for innovative learning and research projects.

\section{Strategic knowledge management system as a means of ensuring the competitiveness of railway transport}

The strategic approach to knowledge management in railway transport is implemented through ensuring the relationship of knowledge management with the strategy of Ukrzaliznytsia JSC and the needs of external stakeholders. In particular, it establishes causal relationships between knowledge and needs of external stakeholders, identifies key 
knowledge needed to implement the strategy and identifies a gap in key knowledge [10]. Given the above provisions, we present the author's approach to the formation of the concept of knowledge management in railway transport (Fig. 1).

\begin{tabular}{|c|c|c|c|}
\hline \multicolumn{4}{|c|}{ Subject of management - managers of all levels } \\
\hline \multicolumn{4}{|c|}{ Objects } \\
\hline $\begin{array}{l}\text { staff competencies (professional; } \\
\text { communication; corporate; spiritual and } \\
\text { motal) }\end{array}$ & $\begin{array}{l}\text { information } \\
\text { resources }\end{array}$ & $\begin{array}{l}\text { communication and } \\
\text { information systems }\end{array}$ & $\begin{array}{c}\text { risks of } \\
\text { knowledge loss }\end{array}$ \\
\hline \multicolumn{4}{|c|}{$\begin{array}{l}\text { Principles: scientific; systematic; situational; understanding and use of psychological factors; authority } \\
\text { and responsibility; de emocratic centralism; integration; development of conditions and opportunities; } \\
\text { ensuring the novelty of knowledge; rewards for knowledge; turning knowledge into action }\end{array}$} \\
\hline
\end{tabular}
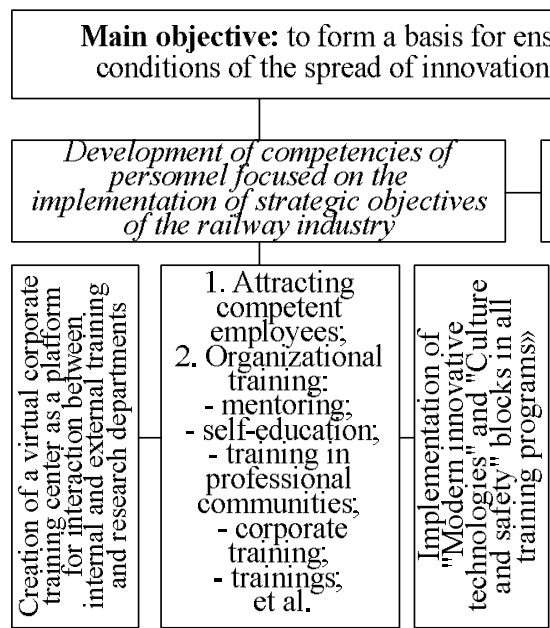

1. Attracting
competent
employees;
2. Organizational
training:
- mentoring;
- self-education;
- training in
professional
communities;
- corporate
training;
- trainings;
et al.

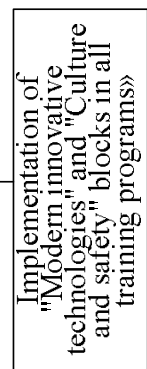

Creation of an integrated information environment to improve the quality of business processes of ERT

\section{- formation of arrays of} information;

- structuring information:

- introduction of

innovative information technologies:

- ensuring internal and

external interoperability

of information systems:

- organization of access and work with information;

- organization of information storage


communication channe

formal, informal; etc.)

- organization of new channels:

- development of

effective communication models;

- development of

strategic cooperation

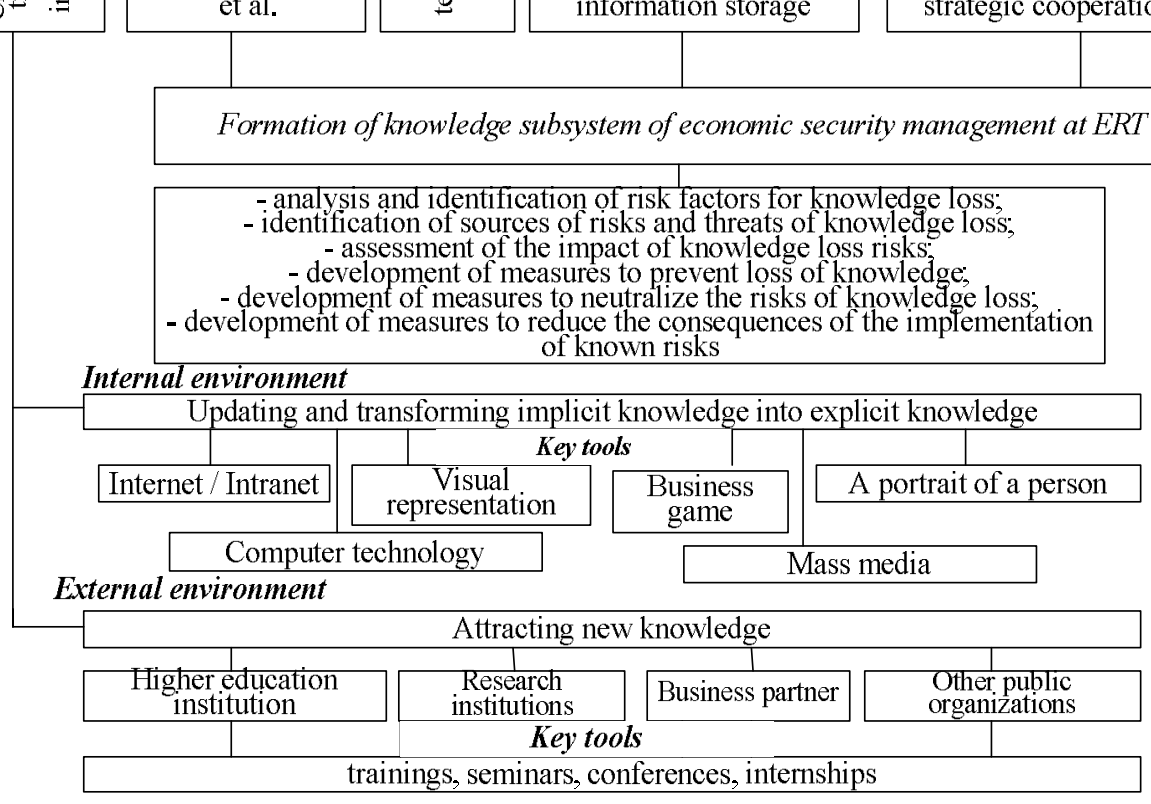

Fig. 1. Formation of strategic knowledge management system in railway transport 
The subjects of knowledge management at railway transport enterprises are the top managers of all levels of the management hierarchy. The object of management identified the competence of personnel, information resources, information and communication systems and the risks of loss of knowledge of railway transport enterprises. The main goal of knowledge management should be the formation of a basis for ensuring the competitiveness of railway transport in the conditions of the spread of innovation and information progress of post-industrial society. The objectives of knowledge management in railway transport should be defined: development of competencies of personnel focused on the implementation of strategic objectives of the railway industry; creation of a comprehensive integrated information environment that improves the quality of business processes of railway transport enterprises; implementation of effective interaction of railway transport enterprises with stakeholders to improve the image of the railway industry; formation of knowledge subsystem of economic security management at railway transport enterprises.

A huge number of authors consider training to be the main source of knowledge for the enterprise. The relationship between knowledge management and the staff development function as an element of the personnel management system is not in doubt. To implement the concept of knowledge management based on the personnel management system, the key functions of the system are the functions of personnel development, evaluation, motivation and regulation of social and psychological processes. The formation of knowledge in the process of development of staff competencies occurs as a result of attracting competent employees, and as a result of organizational training.

In the light of modern approaches, organizational learning can be seen through the prism of comprehensive employee ownership of knowledge management through their comprehensive development and corporate learning.

It should be noted that in order to provide the industry with qualified specialists in the Ukrainian railway transport, an integrated system of training for the industry was created, an industry program for improving the material and technical base of educational institutions was developed, which is aimed at strengthening the direct connection between the enterprises of railway transport and educational institutions by transferring devices and equipment, normative and technical documentation, performing repair work on the reconstruction of educational buildings, dormitories.

The system of organizational training in the system of Ukrzaliznytsia JSC should cover mentoring, self-education, training in professional communities, corporate training, trainings, etc. Indicative activities in the field of organizational training:

1. Development of new knowledge, transformation of implicit knowledge into explicit: identification of gaps in knowledge; conducting research; synthesis of information, the results of various studies and the development of new knowledge; conducting research that is valuable for management processes and publication of their results; conducting specialized reviews of the results of research; providing participants with the results of research.

2. Dissemination of best practices: benchmarking: search for partners, concrete examples of best practices; documentation of best practices; compilation and dissemination of experience.

3. Meetings and seminars: implementation of training programs based on feedback from the audience; organization of video seminars; conferences, meetings with experts on topical issues.

An effective mechanism of formalization of corporate knowledge can be a virtual training center of Ukrzaliznytsia JSC. In the context of the development of the "knowledge economy" it is advisable to understand the training center as not just a training structural unit, but a platform for interaction with other economic agents, consulting companies, 
educational institutions, professional associations in the direction of joint design of the corporate training and development system. The basis for ensuring the competitiveness of railway transport enterprises and the formation of its strategic advantages in the long term is the constant updating of knowledge. It is possible to carry out in full the specified by means of the offered conceptual provisions of strategic management of knowledge at the enterprises of railway transport opening the administrative technologies in the directions: development of competences of the personnel focused on implementation of strategic tasks; creation of a complex integrated information environment, ensuring the quality of business processes; implementation of effective interaction of railway transport with stakeholders to improve its image; formation of knowledge subsystem of economic security management.

\section{References}

1. V.L. Dykan, I.V. Tokmakova, V.O. Ovchynnikova, M.V. Korin, A.V. Tolstova, Osnovy biznesu, Kharkiv, 291 (2018)

2. M. Porter, Competitive strategy: techniques for analyzing industries and competitors Alpina-Business-Books, 454 (2005)

3. V.G. Shynkarenko, A.S. Bondarenko, Upravleniye konkurentosposobnostyu predpriyatiya. Kharkiv, 186 (2003)

4. N.E. Kalycheva, Scientific Bulletin of Kherson State University, 27, 139-142 (2017)

5. E.M. Sych, Bulletin of Kharkiv national University named after V. N. Karazin, 512, 152-154 (2001)

6. V.L. Dykan, The bulletin of transport and industry economics, 43, 11-20 (2013)

7. L.Edvinsson, M. Malone, Intellectual Capital: realizing your company's true value by fi nding its hidden brainpower, N.Y.: Harper Business, 230 (1997)

8. K. Wiig, Journal of Knowledge Management, 1, 6-14 (1997)

9. L.A. Trofimova, V.V. Trofimov, Knowledge Management: textbook, SPb.,77 (2012)

10. V.O. Zadoya, Problems of transport Economics, 9, 71-76 (2015) 